\title{
Analytical Study of Early Kick Detection and Well Control Considerations for Casing while Drilling Technology
}

M Azab ( $\sim$ Hany.AzMa@pme.suezuni.edu.eg)

\section{Case study}

Keywords: Casing while Drilling, Conventional Drilling, Kick Tolerance, Early Kick Detection, Well Control

Posted Date: August 26th, 2021

DOI: https://doi.org/10.21203/rs.3.rs-845731/v1

License: (a) (i) This work is licensed under a Creative Commons Attribution 4.0 International License.

Read Full License 


\title{
Analytical Study of Early Kick Detection and Well Control Considerations for Casing while Drilling Technology
}

\author{
Said K. Elsayed \\ Faculty of Petroleum and mining Engineering, Suez University, s.salem@suezuni.edu.eg \\ Adel M. Salem \\ Faculty of Petroleum and mining Engineering, Suez University, adel.salem@suezuni.edu.eg \\ Hany M. Azab
}

Faculty of Petroleum and mining Engineering, Suez University, Hany.AzMa@pme.suezuni.edu.eg

\begin{abstract}
Recently, casing while drilling $(\mathrm{CwD})$ technology has been employed to reduce drilling time and expenses. These intelligent drilling technique improved wellbore stability, fracture gradient, and formation damage while reducing exposure time but when a well control issue arises, the differences in wellbore geometries and related volumes compared to regular conventional drilling procedures necessitate a distinct strategy.

In this paper, the essential well control parameters were provided for casing while drilling operations, presents simplified method that has been developed to evaluate the maximum kick tolerance (KT) for both conventional and casing while drilling techniques using a mathematical derivation, the narrow annular clearance, in contrast to drilling with a conventional drill string would impair kick detection and handling operations. Furthermore, the large disparity in kick tolerances should be carefully evaluated in order to avoid lost circulation/kick cycles as well as examine and evaluate technical approaches to early kick detection (EKD) studying how they relate to safety, efficiency, and reliability in a variety of common casing while drilling operations.
\end{abstract}

According to preliminary findings, by utilizing casing while drilling technology and compared to identical well was drilled conventionally using drill pipe, the annulus pressure loss (APL) is average 3 times of the conventional drilling technique. Furthermore, kick tolerance is reduced by $50 \%$ and maximum allowable well shut-in time reduced by $65 \%$ necessitating early kick detection.

\section{Keywords:}

Casing while Drilling, Conventional Drilling, Kick Tolerance, Early Kick Detection, Well Control 


\section{Introduction}

As the industry evolves toward reservoirs that are deeper, more complicated, and more expensive to develop, there is an increasing demand for technical solutions that enable effective drilling and completions while lowering risks and costs to a minimum. Casing while drilling $(\mathrm{CwD})$ technologies mitigate drilling problems by providing capabilities that go beyond the norm, allowing casing to achieve total depth (TD) efficiently, optimizing the well architecture efficiently as shows in Figure 1. ${ }^{[1]}$

Furthermore, Casing while drilling may be best adapted solution to drill soft formations, which are experienced at the top hole sections of the well and are concerned with various hole problems. ${ }^{[2]}$

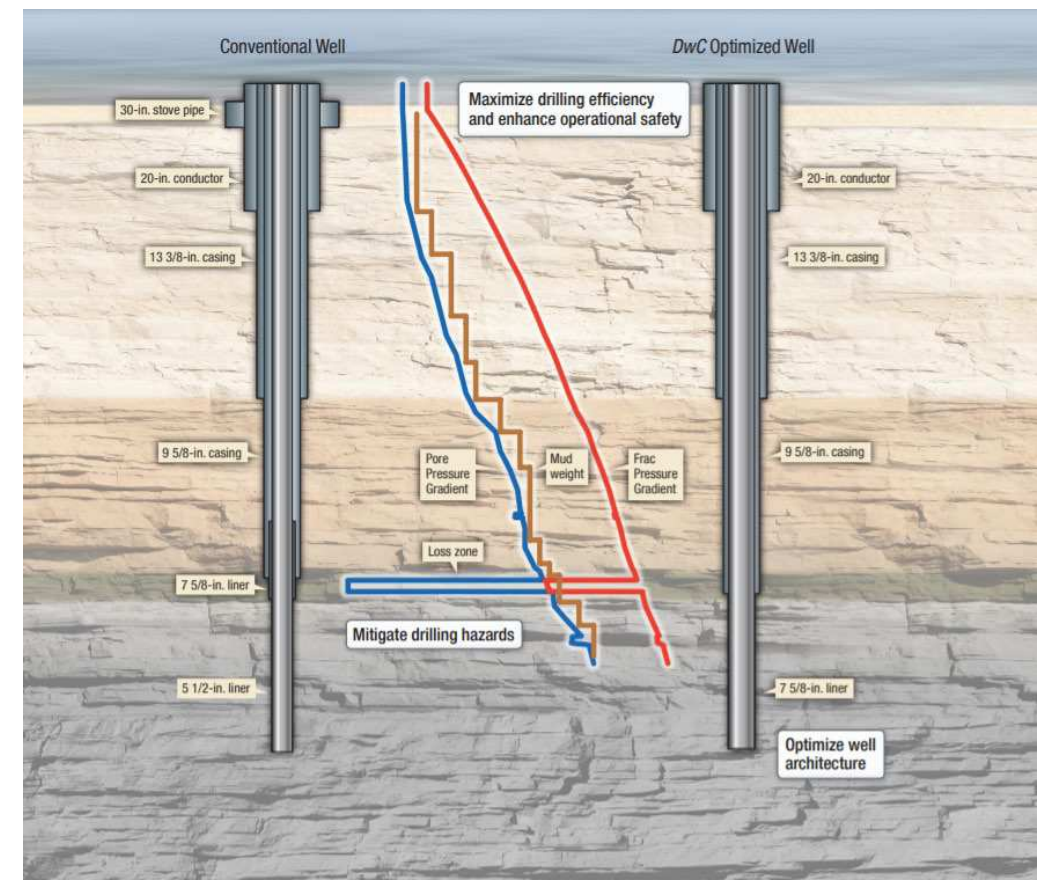

Figure 1: Conventional Drilling Vs Casing while Drilling

In Casing While Drilling operations, the casing is used as drill string, the required energy (hydraulic and mechanical) is provided by the top drive system from the surface to the casing string and its drill bit. A pilot bit, under-reamer, stabilizers, and drill lock assembly (DLA) are typically included in a casing while drilling bottom hole assembly (BHA) as shows in Figure 2. DLA is a hydraulically sealed connection between the drilling assembly and the casing strings Figure 3

For the surface and intermediate hole sections, an underreamer is utilised above the pilot bit to open the hole to the final desired wellbore diameter. ${ }^{[3]}$

On the side of mud circulation, drilling fluid is pumped down the drill string and circulated up through the annulus, just like in conventional drilling. This improvement in pipe 
handling enhances well site safety while also allowing drillers to use regular rigs size or smaller rigs designed expressly for casing drilling. ${ }^{[4]}$
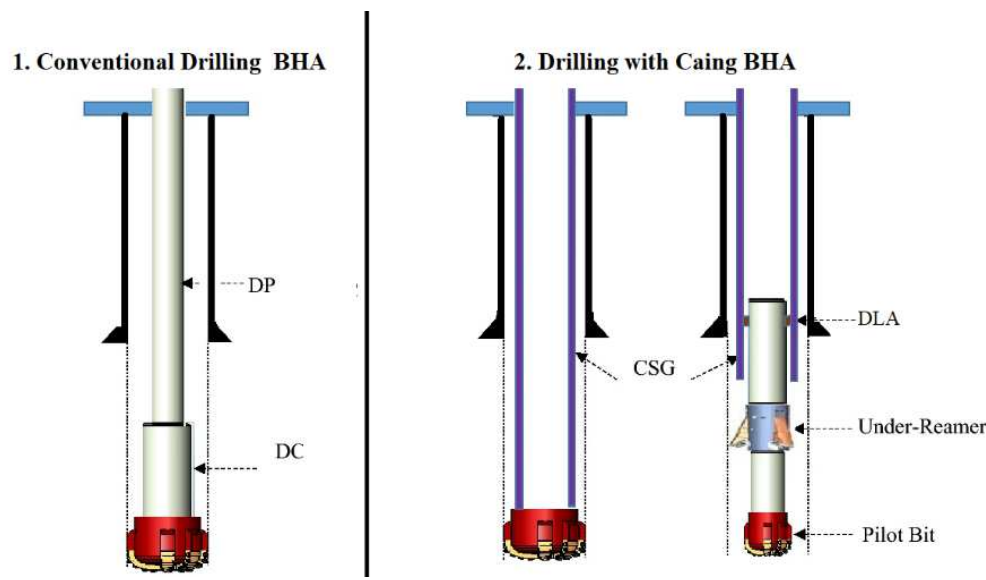

Figure 2: Conventional drilling BHA Vs Casing while drilling BHA

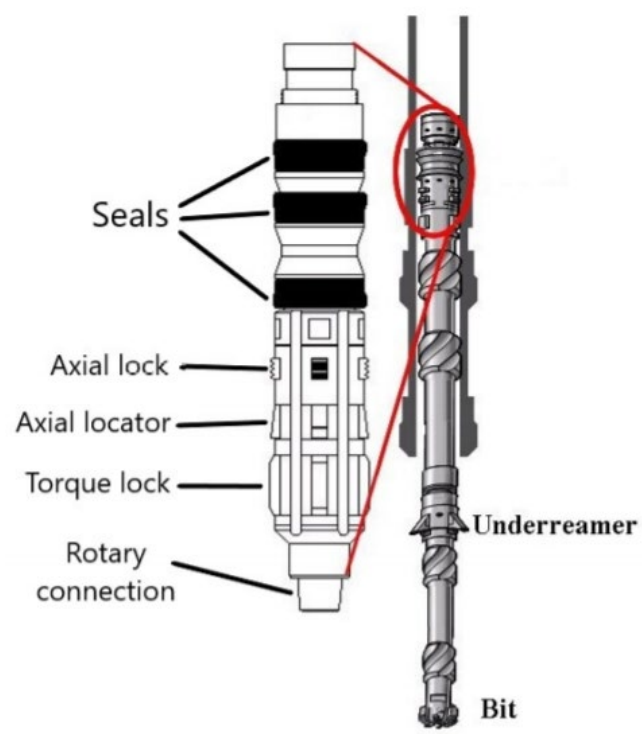

Figure 3: Drill lock assembly

\section{History of casing while drilling technology}

Casing while drilling technology has been effectively used in a number of challenging wells to drill through problematic well sections that would have been impossible to drill using conventional drill pipe methods minimizing trip time and operational costs.

Since its initial field experiments in 1990 (Warren et al, 2001), CwD technology has evolved to meet a variety of drilling problems and obstacles, to the point where it can drill from one casing shoe to the next in a directional hole with a curve section. ${ }^{[5]}$

The first steps toward establishing this new method were taken in the $1890 \mathrm{~s}$, when engineers studied a new strategy based on rotary drilling to drill a well with casing and then retrieve the 
hydraulically expanded bit (Tessari \& Madell, 1999). A further patent was presented a few decades later, in 1926, which added a retrievable and re-runnable casing bit. ${ }^{[6]}$

In 2001, BP and Tesco recorded drilling surface and production casing intervals for 15 gas wells in the Wamsutter area of Wyoming, USA, utilising casing while drilling technique. The depths of these wells varied from 8200 feet to 9500 feet (Shepard et al. 2001). Shell Exploration and Production Company significantly improved drilling efficiency in south Texas at the same period by drilling underbalanced with casing, resulting in a cost decrease of about $30 \%$. (Fontenot et al. 2005). ${ }^{[7]}$

Different operators used casing to drill more than 2000 wellbore sections till 2005. More than 1020 of these intervals were drilled vertically with casing and non-retrievable system, approximately 620 intervals were drilled with partial liners, more than 400 intervals were drilled vertically with a retrievable system, and about 12 intervals were drilled directionally with a retrievable system. All of these early uses aided casing while drilling's evolution from a novel technology with questionable reliability to a feasible solution that can save costs, improve drilling productivity, and reduce rig downtime (Fontenot et al. 2005). ${ }^{[7}$

\section{Types of casing while drilling system}

The casing is normally put into rotary motion and cemented in the well at the desired total depth (TD), however there are now a variety of developed casing drilling types. As illustrated in Figure 4, those models can be split into two types. ${ }^{[6]}$ : -

1. Retrievable system

If the desired target depth is reached, the Bottom hole assembly (BHA) that is attached to the first joint of the casing string with DLA can be retrieved using a wireline unit (wireline retrievable system) or drill pipe.

2. Non-Retrievable system

BHA is not recovered in this system; if it is, it is cemented immediately after reaching the necessary depth, and the bit is drilled out if the drilling procedure must be continued. Drillable polycrystalline diamond compact (PDC) bits are a common bit utilised in this technique. 

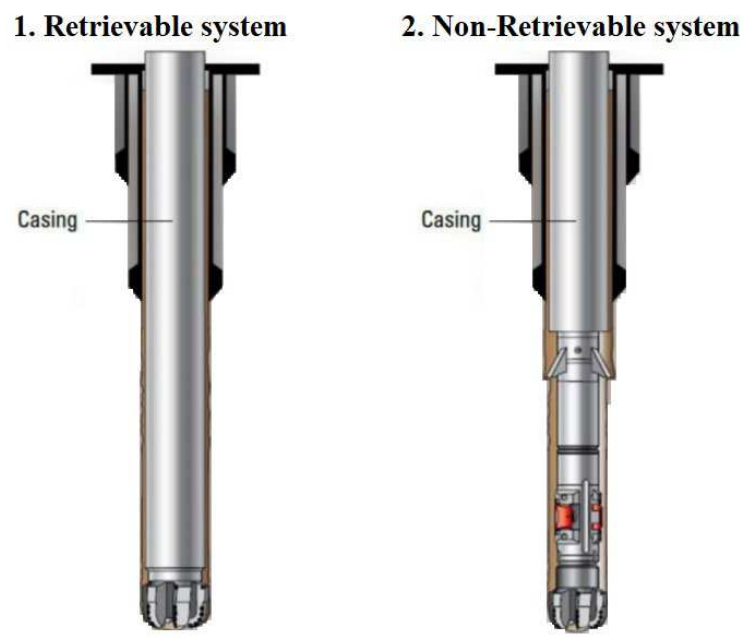

Figure 4: Retrievable and non-retrievable casing while drilling BHA (modified from Fontenot et al. 2005)

\section{Features and benefits of casing while drilling technology}

Despite the fact that there appear to be no significant differences between this technique and the conventional drilling methods using a drill pipe as its backbone, the drilling operation using casing tubulars has become one of our industry's most significant technological revolutions. ${ }^{[8]}$

$\mathrm{CwD}$ may save on rig equipment capital and operational costs by eliminating expenditures involved with acquiring, handling, inspecting, shipping, and tripping the drill-string. ${ }^{[9]}$

According to researchers, $\mathrm{CwD}$ resulted in a $10 \%$ cost reduction and a $30 \%$ time savings [(Lopez and Bonilla. 2010) and (Sánchez et al. 2012)]. Other studies [(Fontenot et al. 2003) and (Karimi et al. 2011)] found that lost circulation was greatly decreased. In addition [(Aadnoy et al. 2009) and (Radwan and Karimi. 2011)] have documented characteristics of successful field implementation of $\mathrm{CwD}$ technology. As well as the suggestion that the fracture gradient has improved (Salehi et al. 2013). ${ }^{[10]}$

The problem of reducing overall well costs while boosting output to maximise the return on investment in well reserves is a major challenge for the oil and gas sector. This has been accomplished to some extent by utilising casing while drilling technology as a solution or as element of other mitigating requirements in drilling operations by: -

\section{A. Reducing drilling time $\&$ increasing efficiency}

Each foot drilled will be cased, making it a two-in-one procedure, allowing sections to be completed faster (Figure 5) and if the casing becomes stuck before reaching the planned setting depth, it can be set and cemented there. As it will be more efficient than tripping out drill pipe out of hole with the possibility of fishing. Meanwhile, the 
unreachable depth can be covered by a casing with a lower diameter that can be run safely. ${ }^{[11]}$

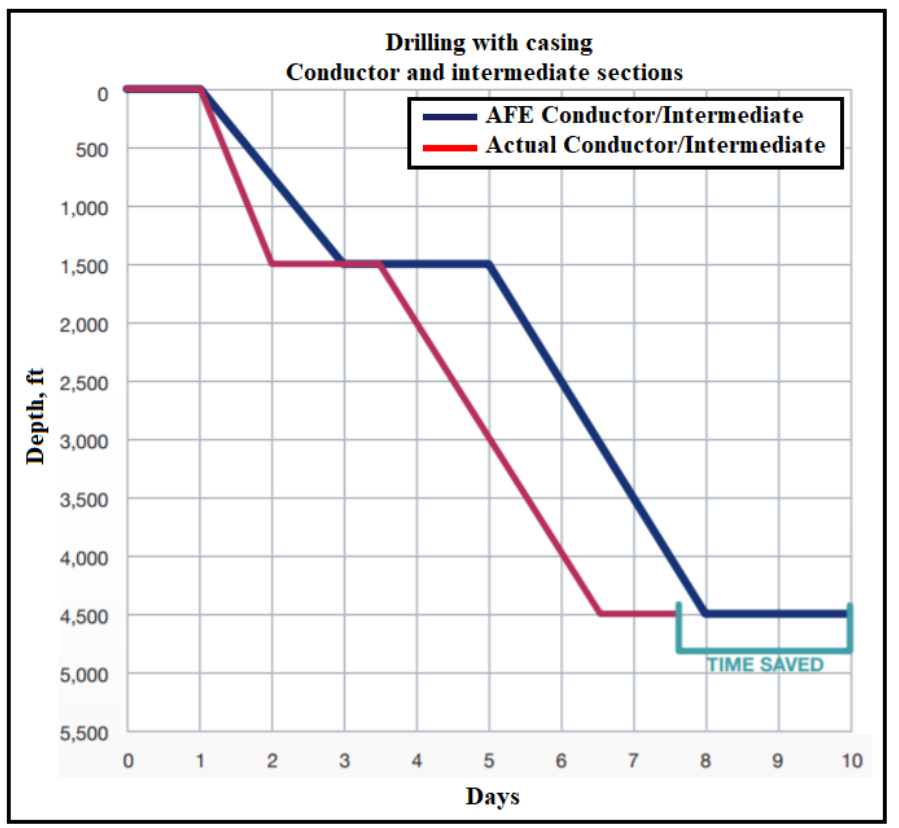

Figure 5: Tesco's CwD practices

\section{B. Controlling casing strings cost}

It's worth noting that the casing used in this approach is of the same grade and weight as the casing used throughout conventional drilling. As a result, in case of casing while drilling approach, there is no further or extra cost for a casing string to be used (Tessari et al., 1999). ${ }^{[12]}$

\section{Reducing cementing costs}

The problem of reducing overall well costs while boosting output to maximise the return on investment in well reserves is a major challenge for the oil and gas sector. This has been accomplished to some extent by using casing while drilling as a solution as the smaller annulus requires less cement and has less cement excess compared to conventional drilling. ${ }^{[13]}$

\section{Improving borehole cleaning efficiency.}

$\mathrm{CwD}$ has a lower annular clearance between the casing and the borehole wall (Figure 6), resulting in enhanced annular velocity and borehole cleaning efficiency. As a result, the likelihood of a stuck pipe is reduced. ${ }^{[13]}$ 


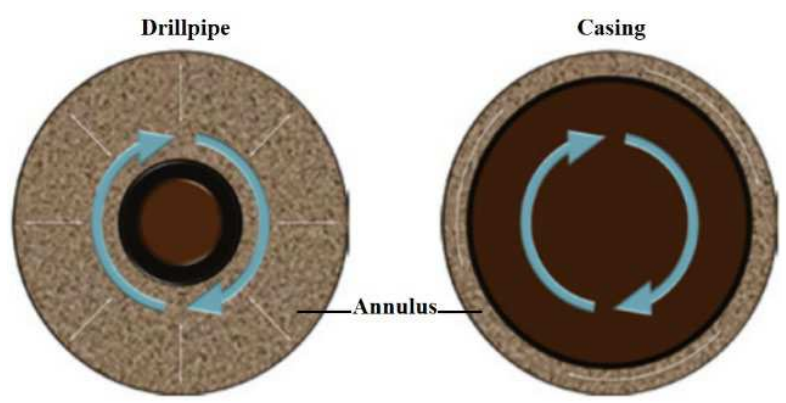

Figure 6: In casing while drilling, the annulus is narrower than in conventional drilling.

\section{E. Improving wellbore stability}

It may eliminate hole problems associated with tripping when the (BHA) needs to be replaced or when the TD is reached, As most wellbore instability and stuck pipe difficulties occur during tripping drill string in/out relates to non-productive time (NPT). ${ }^{[14]}$

\section{F. Reducing lost circulation}

Casing while drilling helps to minimize mud loss into the formation. The Plastering Effect produces a high-quality mud cake that seals the wellbore and prevents fluid transfer between it and the formation wall. In the worst-case scenario, where the losses are incurable, drilling will continue with minimal losses until the casing reaches the proposed total depth. As a result, problems and dangers associated with swab, pit volume monitoring, hole volumes, and fill up related to steel removed from the wellbore in a lost circulation condition, such as hole collapse and stuck pipe, are no longer a concern. ${ }^{[15]}$

\section{Plastering/smearing effect}

When the casing string rotates with limited annulus clearance, The casing contact strengthens and enhances the wellbore's integrity, while the plastered filter cake (Figure 7) decreases permeability at the wellbore zone, improving the fracture gradient and allowing for a wider mud weight window, eliminating any possible loss circulation (Figure 8) and well control events referring to "Plastering/Smearing Effect". [16]

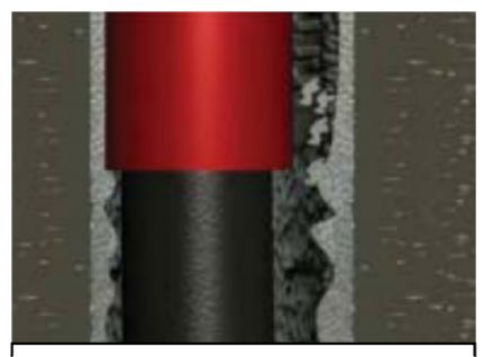

Fig. 1-A: Casing is forced against the bore wall as it advances into the borehole.

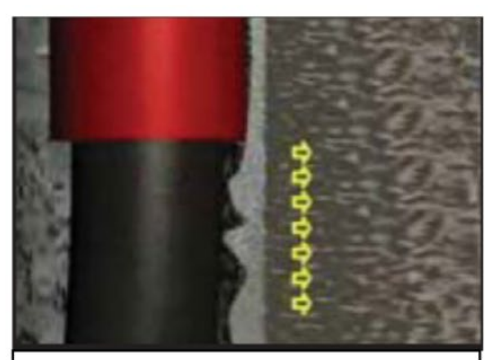

Fig. 1-B: As mud is smeared into the formation, filter cake builds up on the borehole wall.

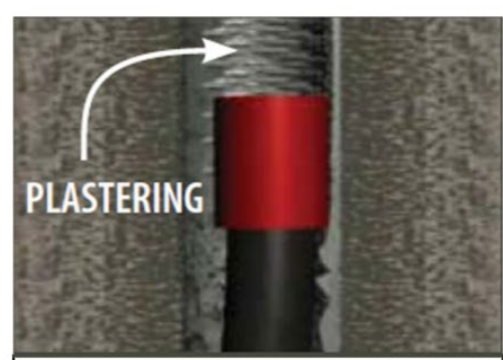

Fig. 1-C: Filter cake and cuttings are plastered against the borehole wall, sealing porous formations. 


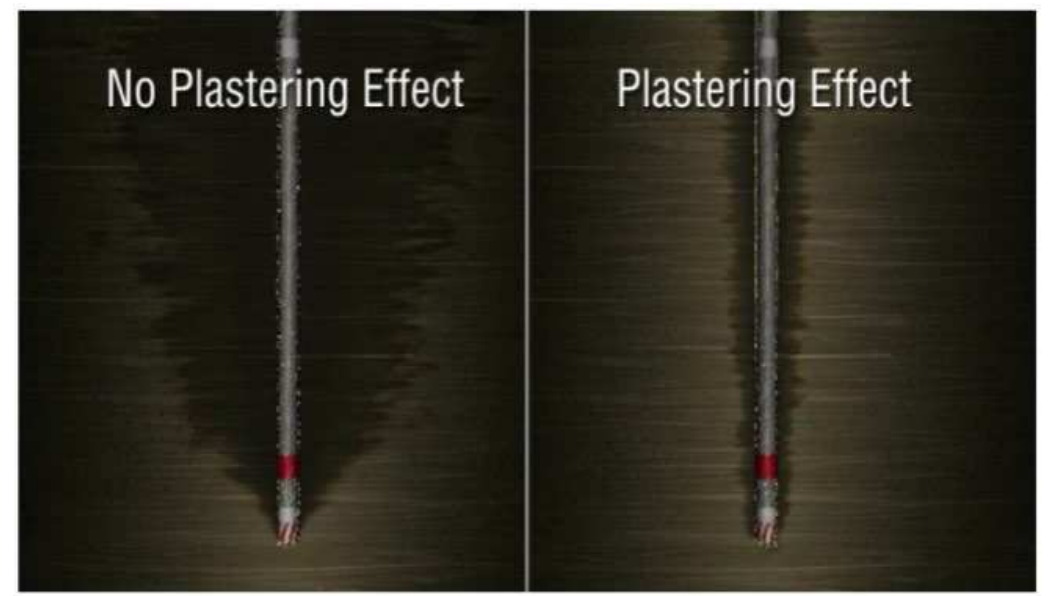

Figure 8: Plastering effect eliminate loss circulation

\section{G. Rig Power Demand}

Because of the reduced circulating pressure and elimination of periodic draw-works tripping, the rig requires less horsepower and thus less maintenance and fuel cost. ${ }^{[17]}$

\section{Well control for casing while drilling and problem statement}

Well control is represented as a series of techniques for reducing a hydrocarbon wellbore's "kick potential" and keeping it under control in the event of an unexpected flow of reservoir fluids into the wellbore during drilling, completion, workover, or service activities. It entails the use of procedures, techniques, processes, and equipment to ensure that field operations and environment are safe. ${ }^{[18]}$

Today the oil and gas business grows, new and creative drilling technology are used to drill oil wells in challenging environments. To deal with the kick of hydrocarbon fluids from the formation in the well bore during drilling, every drilling technology requires a comprehensive well control design which covered in this study.

Over $70 \%$ of kick events occur when tripping in/out of the hole, as is well reported. In CwD, the string's bottom end is always in the bottom of the hole. As a result, when $\mathrm{CwD}$ is used, the chances of kick events are reduced but still the study of allowable response time to a kick is a vital part of this study. ${ }^{[3]}$

When $\mathrm{CwD}$ technique is used instead of conventional drilling method, a modification in overall wellbore geometry (e.g. impact of Threaded, drill pipe sizes \& Coupled connections in wellbore geometry (Grijalva, 2017)) is seen in Figure 9, this condition is crucial for well control-related methodologies and procedures. As a result, it's critical to understand the distinctions between conventional drilling and $\mathrm{CwD}$ in terms of well control and its monitoring system, As Blowout will occur if the well control system fails to early detect the kick 
(formation pressure greater than wellbore pressure) and terminate it quickly and effectively. [19]

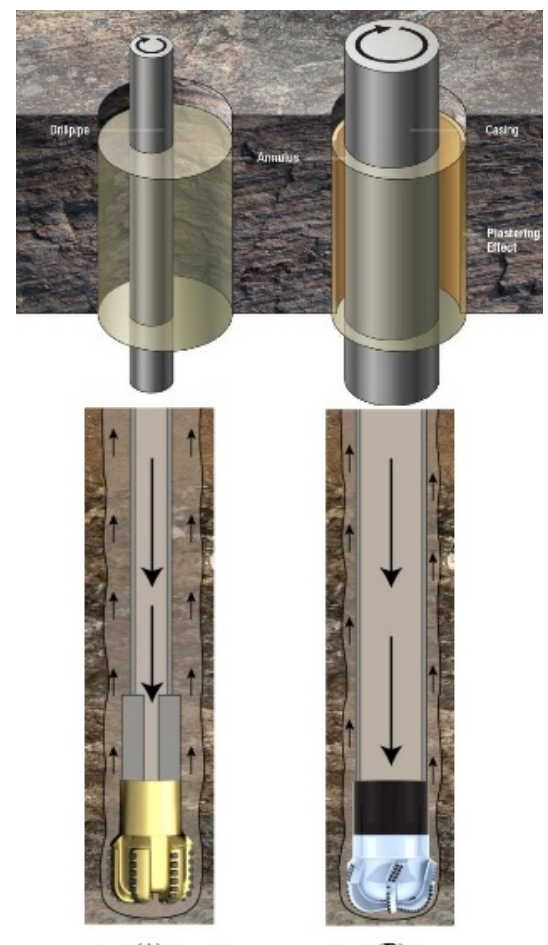

(A)

(B)

Figure 9: (A) Conventional drilling, and (B) CwD wellbore geometry (Karimi et al. 2012).

There are many definitions have been given to describe kick tolerance (KT); however, for practical purposes, kick tolerance can be defined as the largest kick volume that can be tolerated without breaking the prior casing shoe. ${ }^{[20]}$

Regardless of which kick tolerance definition is used by an engineer during well design, a common philosophy is that any design has an imaginary technical boundary around it, and that making changes outside of this design boundary envelope risks related to well integrity and operational safety during well planning. ${ }^{[21]}$

Furthermore, there is a risk of misrepresenting the significance of the unique combination of historical events and effects. This is risky because just a 50 bbls kick did not result in a blowout under particular conditions does not mean that a 5 bbls improperly handled under identical conditions would not result in a disastrous blowout, and vice versa. In general, the occurrence of one set of events and their consequences may or may not have an impact on succeeding sets of events. These distinct combinations are often effected by kick tolerance definition ${ }^{[21]}$

Recently, KT has been employed to determine casing setting depths during well design making the drilling operation safer as the quantity of the kick volume that enters the well can be determined by: the underbalance between mud weight and formation pressure; reservoir 
properties (porosity \& permeability); influx type (gas, oil or water); kick detection equipment sensitivity and reliability; and well control crew reaction time. ${ }^{[22]}$

Effective early kick detection (EKD) and blowout prevention are among the most important oilfield activities, as failure to do so can result in costly human, material, and financial losses, as well as potential pollution. ${ }^{[23]}$

The necessity of quickly detecting and responding to a kick is commonly regarded in the industry, and many businesses understand this keep track of a range of kick-related variables (e.g., size of kicks taken, operations and its intensity)

The main Key Performance Indicators (KPIs) for kick safety that necessitate special attention and regular monitoring ${ }^{[10]}$ : -

1. Kick Detection Volume (KDV): How much influx volume happens before a kick is positively detected?

2. Kick Response Time (KRT): How long does it take after a kick has been positively detected before the influx is stopped by well-controlled procedures?

In any discipline of engineering, no design is created to accommodate systemic abuse. When it comes to crew response time, awareness, and equipment reliability, the designer will have to make some acceptable assumptions. He understands that crew preparation, training, and competency must be proved prior to beginning on an operation. He may then justify the variability in kick detection system performance and crew response time in statistical terms after putting in place a framework of procedures to prevent gross errors. ${ }^{[24]}$ 


\section{Approach}

In this paper, the main objective and scope has been limited to the maximum allowable well shut-in time as a measure of kick tolerance and influx flow rate, looking into well control consideration in simulated vertical well that was drilled conventionally and using casing while drilling technology. Using a single phase kick tolerance model, a water-based mud (WBM) with a gas kick is considered to eliminate difficulties caused by gas solubility, evaluating the maximum kick tolerance and allowable well shut-in time for each drilling technique.

\section{Research methodology}

When casing while drilling is utilized, the annular pressure loss is found high relative to conventional drilling because the annulus between the borehole and the casing string is relatively narrow (Figure 10), resulting in increased bottom hole pressure and reduced kick tolerance.

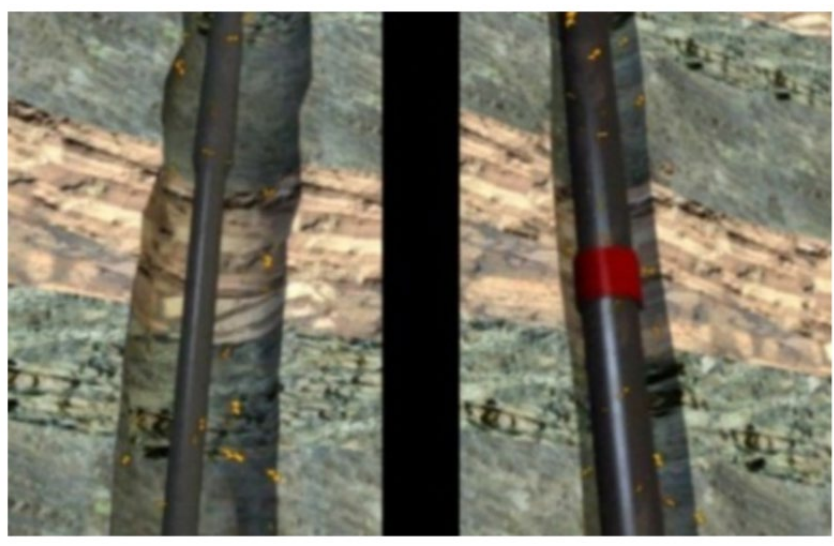

Figure 10: Borehole wall clearance comparison between Casing while drilling (right) and conventional drilling (left).

Because of its consequences in well design, drilling, and well control, kick tolerance has lately gained in importance in well operations. This article aims to expand understanding about Kick Tolerance and serves as a technical foundation for casing while drilling by investigating a simple method for applying the kick tolerance idea in an effective way based on field data.

EKD is one of the most critical areas for well control safety enhancement. As more operations are undertaken in casing while drilling operations, the requirement for earlier, more effective, and more dependable kick detection across a wide variety of drilling operations has really become increasingly crucial. ${ }^{[22]}$

In well control planning process, allowable well shut-in time is one of the key parameters in well control considerations during drilling operations. The methodology given in this article 
comprises the use of gas flow deterministic models combined with maximum kick tolerance to investigate the likelihood of the undesired well flow during deploying casing while drilling operations.

\section{Mathematical Derivation of kick tolerance and allowable well shut-in time}

Kick tolerance mathematical model for a theoretical well drilled with casing can be seen in this practical section. Calculations such as annular pressure loss, bottomhole pressure, kick height, kick tolerance and allowable well shut-in time based on influx flow rate and compared to conventional drilling method.

In present work, the kick tolerance model is developed with following assumptions:

1. Gas compressibility factor " $Z$ " = 1

2. Single phase kick tolerance model

3. Poisson ratio $(\mathrm{V})=0.4$

4. Overburden stress gradient $(\sigma)=1 \mathrm{psi} / \mathrm{ft}$

5. Gas compressibility factor " $Z$ " $=1$

6. Drillpipe $\mathrm{OD}=5$ inch

Following the model assumptions, a simplified Mathematical Derivation method is developed and presented in the following section: -

1. Calculate drilling fluid hydrostatic pressure (HP) at kick depth (TVD kick$\left._{\text {. }}\right)$ using Equation.1

$$
H P=0.052 * \rho \text { pmud } * \text { TVDkick } \quad \text { Eq. } 1
$$

2. According to annular velocity, mud rheology and drill string configuration, determine Annular Pressure Loss (APL) at kick depth $\left(\right.$ TVD $\left._{\text {kick }}\right)$ using Equation.2

$$
A P L=\frac{\left(1.4327 * 10^{-7}\right) * \rho \text { mud } * \text { TVDkick } * A V^{2}}{\text { Dhole }- \text { Dpipe }} \quad \text { Eq. } 2
$$

3. Based on APL value, calculate bottom hole pressure (BHP) using Equation.3

$$
B H P=H P+A P L \quad E q \cdot 3
$$

4. For a kick depth (TVD $\left.{ }_{\text {kick}}\right)$, find formation pressure (FP) using Equation.4

$$
P f=F P G * T V D k i c k \quad \text { Eq. } 4
$$

5. Calculate formation fracture gradient (FG) at previous casing shoe by using Hubbert and Willis method Equation.5 


$$
F G=\left(\frac{\mathrm{V}}{1-\mathrm{V}}\right) *\left(\frac{\text { poverburden }-P f}{D}\right)+\frac{P f}{D} \quad E q .5
$$

6. Determine the maximum kick height at previous casing shoe $\left(\mathrm{H}_{\text {kick }}\right)$ using Equation.6

$$
\text { Hkick }=\frac{0.052 * \rho \mathrm{mud} *(\text { TVDkick }- \text { TVDshoe })+F G * \text { TVDshoe } * 0.052-\text { Pf }}{0.052 * \text { pmud }-G} \text { Eq.6 }
$$

7. Calculate kick volume $\left(\mathrm{V}_{1}\right)$ at casing shoe from the kick height using Equation.7

$$
V 1=\text { Ca } * \text { Hkick Eq.7 }
$$

Where:

$$
C a=\frac{D h^{2}-D p^{2}}{1029.4} E q .8
$$

8. By using Boyle Boyle's Law, At bottom hole conditions the kick volume (V2) is given by Equation.9: -

$$
\frac{P 1 * V 1}{T 1}=\frac{P 2 * V 2}{T 2} \quad E q .9
$$

Based on the result of equation. $7 \& 9$

Select the smaller value of kick volume to be the maximum allowable kick tolerance.

9. Calculate maximum allowable annular surface pressure (MAASP) with zero kick volume using equation. 10 and draw graph of MAASP \& kick tolerance relationship

$$
\text { MAASP }=0.052 *(F G-\rho m u d) * \text { TVDshoe Eq.10 }
$$

10. According to Radial flow model (Figure 11) and based on formation properties, the influx flow rate (Qinflux) can calculates using Equation.11

$$
\text { Qinflux }=\frac{0.007 * \mathrm{~K} * \Delta \mathrm{p} * L}{\mu * \ln \frac{R e}{R w} * 1440} \quad E q .11
$$




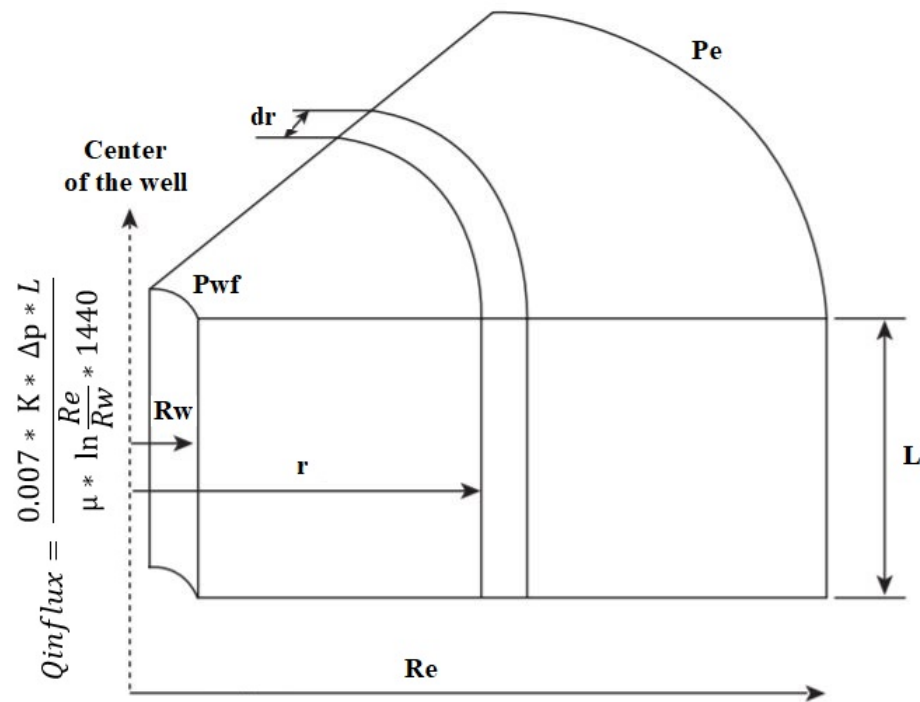

Figure 11: Radial flow model

11. Based on influx flow rate ( $\left.Q_{\text {influx }}\right)$ and After kick tolerance is determined, $5 \mathrm{bbl}$. because of pit gain alarm setting and $1 \mathrm{bbl}$. because of safety reasons have to be subtracted from it. the estimated shut-in time limit can be calculated using Equation.12

Maximum Allowable Well Shut in Time $=\frac{\text { Maximum Allowable Kick Tolerance }}{\text { Qinflux }}$ Eq.12

\section{Field case study}

The well studied in this paper (Well X-2) was planned as a replacement for Well X-1, which was 50 metres away from the surface location of the offset well $\mathrm{X}-1$, Well $\mathrm{X}-1$ had been plugged and abandoned due to a wellbore instability and stuck pipe problems in the intermediate section.

It is sometimes impossible to run the casing through these problematic hole sections, resulting in significant time loss. To achieve successful operations, timely reaming trips are required during drilling and prior to running casing.

To limit the risk of unplanned occurrences of drilling problems in this area, many methods were used, including: -

- Modifying the mud's physical properties,

- Performing several short trips to combat openhole drag forces, and

- Running reaming-while-drilling assembly to ensure a smooth hole condition before running casing to the bottom.

Unfortunately, these methods would increase the likelihood of fishing jobs while having a negative impact on drilling performance and rig downtime. 
After performing multiple attempts to pull out the drillstring without success with severe pack-offs while tripping out, the drilling engineering team decided to deploy Casing while Drilling (CwD) technology in Well X-2 As it has been used successfully in many places to reduce potential non-productive time (NPT), enhance drilling performance and limit unplanned events related to conventional drilling method.

However, this procedure necessitates a precise assessment of the control conditions as well as the hole instability problem, which Casing While Drilling will address. The following description highlights the operational conditions and well control for the considered hole sections when drilled conventionally and utilizing casing while drilling methods.

\section{Planning and Preparation}

During the design stage of this well, a multi-disciplinary technical team analysed two runs utilising conventional and $\mathrm{CwD}$ techniques to evaluate comparative kick tolerance and assess allowable well shut-in time to reach casing point with appropriate well control tracking system as they predicted a high formation pressure at $2145 \mathrm{ft}$ TVD (TVDkick) with a well control risk.

Both technical runs required a thorough planning stage in which the operator and major service companies examined and debated hazard analyses, contingency plans, procedures, and BHA design. The first objective of the project was to demonstrate the $\mathrm{CwD}$ technology's reliability in the view of well control and risk mitigation. This goal will be seen in the following sections.

BHA design, optimum drilling practises, drilling parameters, torque and drag modelling, hydraulics, well control equipment considerations, rig specifications, BHA retrieving and setting operations procedures, logging and cementing were all considered during this planning stage. The involvement of all stakeholders involved in the planning process to ensure the success of the applications of CwD without any well control risk.

\section{Drilling Program}

By using standard rotary BHA, Well X-2 was identified and regularly drilled with a standard wellbore architecture (see Figure 12) in four phases: 26-in, 17 1/2-in, 12 1/4-in and 8 1/2-in.

After the 20-inch shoe had been drilled out the conventionally, the $171 / 2$-in surface phase was successfully vertical drilled with large diameter bit (17-1/2 in roller cone bit) with no well control system, cased with 13-3/8 in. 72\# L80 BTC surface casing at $484 \mathrm{ft}$.

The next section is typically planned to be drilled with 12-1/4 in PDC bit and to be cased with $9-5 / 8$ in intermediate casing. With an anticipated wellbore instability problem, the 
intermediate sections should be designed utilizing CwD technique to set 9-5/8 in casing, 23\# L80 BTC at $2611 \mathrm{ft}$, as shown in Figure 12.

Table 1: Casing configuration

\begin{tabular}{|c|c|c|c|}
\hline $\begin{array}{c}\text { Casing Size } \\
\text { (in) }\end{array}$ & $\begin{array}{c}\text { Casing Weight } \\
\text { (ppf) }\end{array}$ & Casing Grade & $\begin{array}{c}\text { Setting Depth } \\
\text { (ft) }\end{array}$ \\
\hline 20 & 94 & K55 & 79 \\
\hline $133 / 8$ & 72 & L80 & 484 \\
\hline $95 / 8$ & 36 & J55 & 2611 \\
\hline 7 & 23 & L80 & 5842 \\
\hline
\end{tabular}




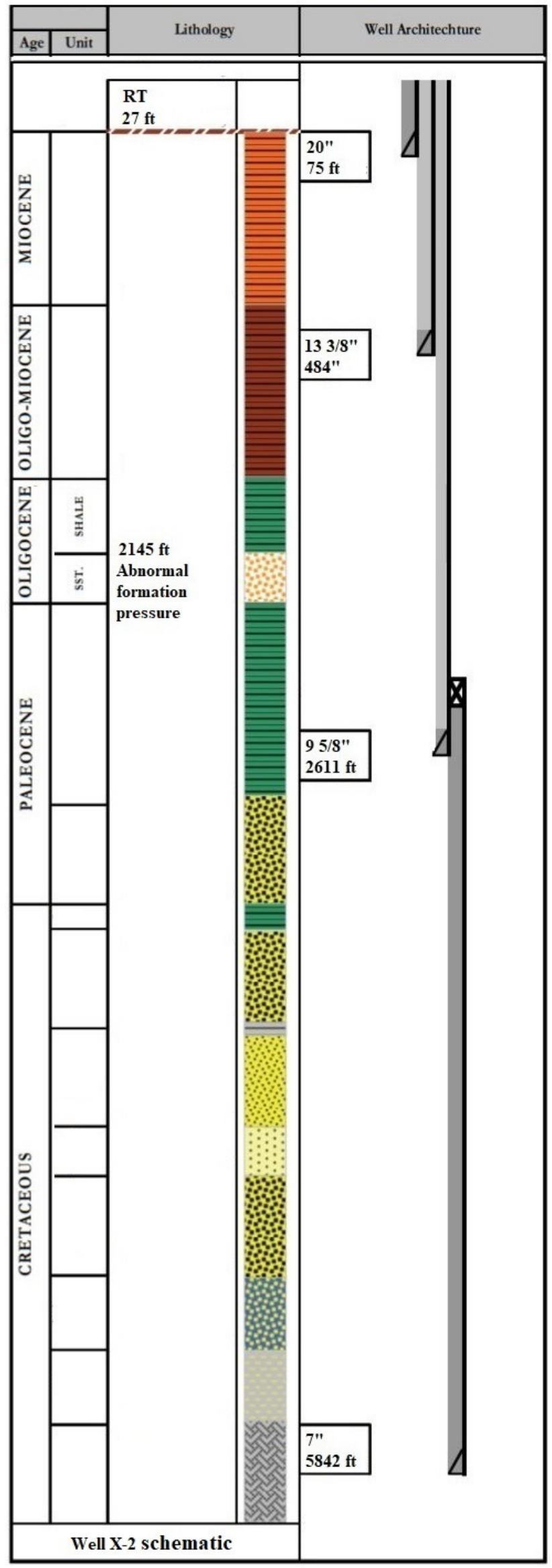

Figure 12: Well schematic 


\section{Formation properties}

Table 2 shows the formation features.

Table 2: Formation properties

\begin{tabular}{|l|l|l|}
\hline Property & Value & Unit \\
\hline Permeability $(\mathrm{K})$ & 500 & $\mathrm{md}$ \\
\hline Gas viscosity $(\mu)$ & 0.3 & $\mathrm{cp}$ \\
\hline Drainage radius $(\mathrm{Re})$ & 400 & $\mathrm{ft}$. \\
\hline Well Bore radius $(\mathrm{Rw})$ & 0.354 & $\mathrm{ft}$. \\
\hline Pressure drawdown $(\Delta \mathrm{p})$ & 200 & $\mathrm{psi}$ \\
\hline Formation pressure gradient $(F P G)$ & 0.433 & $\mathrm{Psi} / \mathrm{ft}$ \\
\hline Gas kick pressure gradient $(\mathrm{G})$ & 0.102 & $\mathrm{Psi} / \mathrm{ft}$ \\
\hline Temperature gradient, & 0.02 & $\mathrm{f} / \mathrm{ft}$ \\
\hline
\end{tabular}

\section{Mud program}

Due to anticipated drilling problems, Inhibited polymer mud was selected to drill $12 \frac{1 / 4}{4} \mathrm{in}$ intermediate section, mud weight is 9.1 ppg were used to drill this section achieving a good hole cleaning by an annular velocity $(\mathrm{AV})=175 \mathrm{ft} / \mathrm{min}$ as shown in Table 3

Table 3: Mud properties

\begin{tabular}{|l|l|}
\hline \multicolumn{2}{|c|}{ 12 1/4-in hole (9 5/8-in Casing) } \\
\hline Depth (MD/TVD), $\mathrm{ft}$ & $484-2611$ \\
\hline Mud Wt, lb/gal & $8.9-9.2$ \\
\hline F. V., seconds & $37-42$ \\
\hline PV@ $120^{\circ} \mathrm{F}, \mathrm{cP}$ & $9-13$ \\
\hline YP @ $120^{\circ} \mathrm{F}, \mathrm{lb} / 100 \mathrm{ft}^{2}$ & $14-20$ \\
\hline API Filtrate, cc/30 min & $4-6$ \\
\hline pH & $9.0-9.5$ \\
\hline MBT, lb/bbl & $10-25$ \\
\hline Chlorides, ppm & $200-1200$ \\
\hline Hardness, ppm & $80-120$ \\
\hline
\end{tabular}

\section{Well control study}

Well control is an important aspect of any drilling project. So many work meetings with key personnel (drilling engineers, company man, rig manager, tool pusher and supervisors, etc.) were held during the planning stage to analyse the risks and response plan for the job and achieve the right response of the key personnel and equipment in the event of a kick or well control incident.

\section{Results analysis and observations}

In order to evaluate the proposed methodology data of the simulated vertical well which had been utilized. Once the data has been collected, the two data sets for conventional and CwD methods were used to implement the proposed methodology as shows in Table 4. 
Table 4: Study results

\begin{tabular}{|c|c|c|c|}
\hline Output Data & Unit & Conventional Drilling Method & CwD Method \\
\hline Hydrostatic Pressure (HP) & $\mathrm{psi}$ & 1015 & 1015 \\
\hline Annular Pressure Loss (APL) & $\mathrm{psi}$ & 11.4 & 32.6 \\
\hline Bottom Hole Pressure (BHP) & $\mathrm{psi}$ & 1026.4 & 1047.6 \\
\hline Formation Pressure (FP) & $\mathrm{psi}$ & 928.8 & 928.8 \\
\hline Fracture Gradient (FG) & $\mathrm{ppg}$ & 15.6 & 15.6 \\
\hline Kick Height (Hkick) & $\mathrm{ft}$ & 673 & 673 \\
\hline Kick Tolerance (KT) & $\mathrm{bbl}$ & 36.6 & 16.8 \\
\hline $\begin{array}{c}\text { Maximum Allowable Surface } \\
\text { Pressure (MAASP) }\end{array}$ & $\mathrm{psi}$ & 163.6 & 4.6 \\
\hline Kick inflow rate (Qinflux) & $\mathrm{bbl/min}$ & 4.6 & 2.3 \\
\hline $\begin{array}{c}\text { Allowable Well Shut-in Time } \\
\text { with 20 ft drilled into } \\
\text { overpressured formation }\end{array}$ & minute & 6.6 & \\
\hline
\end{tabular}

It is vital to fully comprehend the impacts of kick tolerance in the application of casing while drilling in order to provide a safe drilling operations by reducing the danger of unscheduled influx from the formation. Furthermore, because a hypothetical formation breakup can result in circulation losses and a kick event, this value is critical for the reliable execution of well control procedures.

To avoid kick, we must keep the bottom hole pressure higher than the formation pore pressure. To do so, and for planning purposes, it is necessary to develop a kick tolerance graph for each section, as illustrated in Figure13. the kick volume is plotted on the X-axis, and the MAASP is plotted on the Y-axis in that figure. The greatest MAASP determined using Equation 10 is 163.8 psi. For zero maximum allowable surface pressure, is the maximum kick volume as calculated by Equations 8 \& 9, the kick tolerance graph is the straight line that connects points 1 and 2 . 


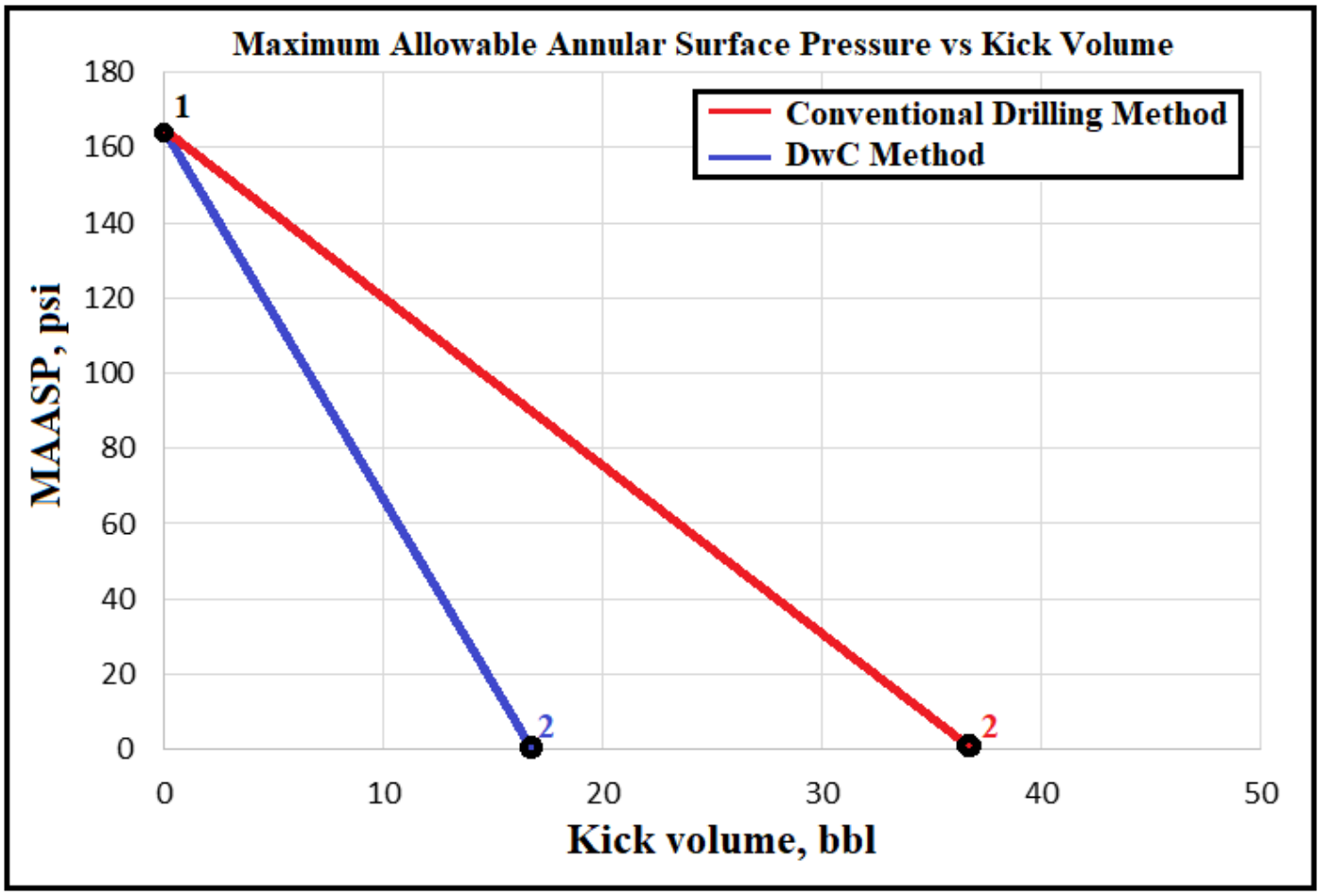

Figure 13: Comparison between Conventional \& Casing while drilling method In terms of well control, the main differences between $\mathrm{CwD}$ and conventional drilling are kick tolerance and maximum allowable well shut-in time. Based on Figure 14, the maximum allowable kick volume at the bottomhole for a conventionally drilled 12-1/4" hole section at $2145 \mathrm{ft}$ is $36.6 \mathrm{bbl}$., compared to $16.8 \mathrm{bbl}$. for a $\mathrm{CwD}$ drilled section. As a result, the maximum allowable kick tolerance for sections drilled with $\mathrm{CwD}$ is only $45.90 \%$ of what would be allowed with conventional drill pipe. As early detection of the kick is critical to a successful well control strategy, it is suggested that the pit gain level alarm be set to the lowest possible value. 


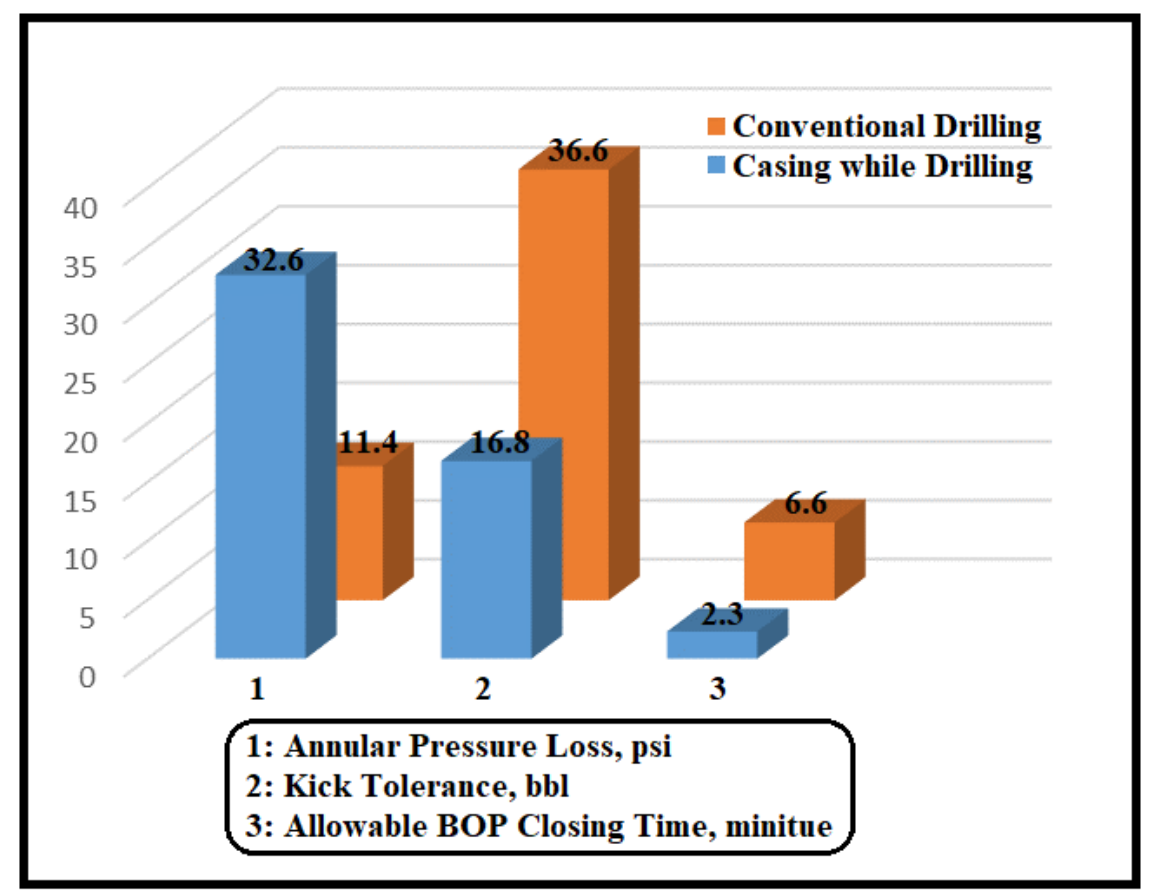

Figure 14: Results analysis

Furthermore, because of the reduced annular capacity, if the kick is gas, the bubble will expand quicker in terms of height, resulting in extremely high surface casing pressures and a reduced MAASP value.

As result of high APL in CwD, pump adjustments should be made to keep constant bottomhole pressure during well control operations.

Another key conclusion is the length of overpressures formation drilled before kick is detected must be taken into account during careful planning as show in Table 5, Because the annulus of a $\mathrm{CwD}$ well is so narrow compared to a conventional well, even a small change in influx volume can result in a huge difference in allowable Blowout preventer (BOP) closing time and well control procedure.

Table 5: Drilled length into overpressures formation vs allowable well shut-in time

\begin{tabular}{|c|c|c|c|}
\hline \multirow{2}{*}{$\begin{array}{c}\text { Length drilled } \\
\text { (ft) }\end{array}$} & \multirow{2}{*}{$\begin{array}{c}\text { Kick inflow rate } \\
\text { Qinflux } \\
\text { (bbl/min) }\end{array}$} & \multicolumn{2}{|c|}{$\begin{array}{c}\text { Maximum allowable well shut-in time } \\
\text { minute }\end{array}$} \\
\cline { 3 - 4 } & & Conventional method & CwD method \\
\hline 1.00 & 0.23 & 132.8 & 46.9 \\
\hline 2.00 & 0.46 & 66.4 & 23.4 \\
\hline 3.00 & 0.69 & 44.3 & 15.6 \\
\hline 4.00 & 0.92 & 33.2 & 11.7 \\
\hline 5.00 & 1.15 & 26.6 & 9.4 \\
\hline 6.00 & 1.38 & 22.1 & 7.8 \\
\hline 7.00 & 1.61 & 19.0 & 6.7 \\
\hline
\end{tabular}




\begin{tabular}{|c|c|c|c|}
\hline 8.00 & 1.84 & 16.6 & 5.9 \\
\hline 9.00 & 2.07 & 14.8 & 5.2 \\
\hline 10.00 & 2.30 & 13.3 & 4.7 \\
\hline 11.00 & 2.54 & 12.1 & 4.3 \\
\hline 12.00 & 2.77 & 11.1 & 3.9 \\
\hline 13.00 & 3.00 & 10.2 & 3.6 \\
\hline 14.00 & 3.23 & 9.5 & 3.3 \\
\hline 15.00 & 3.46 & 8.9 & 3.1 \\
\hline 16.00 & 3.69 & 8.3 & 2.9 \\
\hline 17.00 & 3.92 & 7.8 & 2.8 \\
\hline 18.00 & 4.15 & 7.4 & 2.6 \\
\hline 19.00 & 4.38 & 7.0 & 2.5 \\
\hline 20.00 & 4.61 & 6.6 & 2.3 \\
\hline
\end{tabular}

For example, if 20 feet of overpressured formation is drilled in a CwD scenario, considering the kick inflow rate is $4.6 \mathrm{bbl} / \mathrm{min}$ and the pit level was set at $+/-5 \mathrm{bbls}$ and after the pit level alert, there are just 2.3 minutes to shut-in the well with maximum 16.8 bbls kick volume (Figure15), which is insufficient. In such circumstances, it is suggested that the prior casing shoe be set deeper.

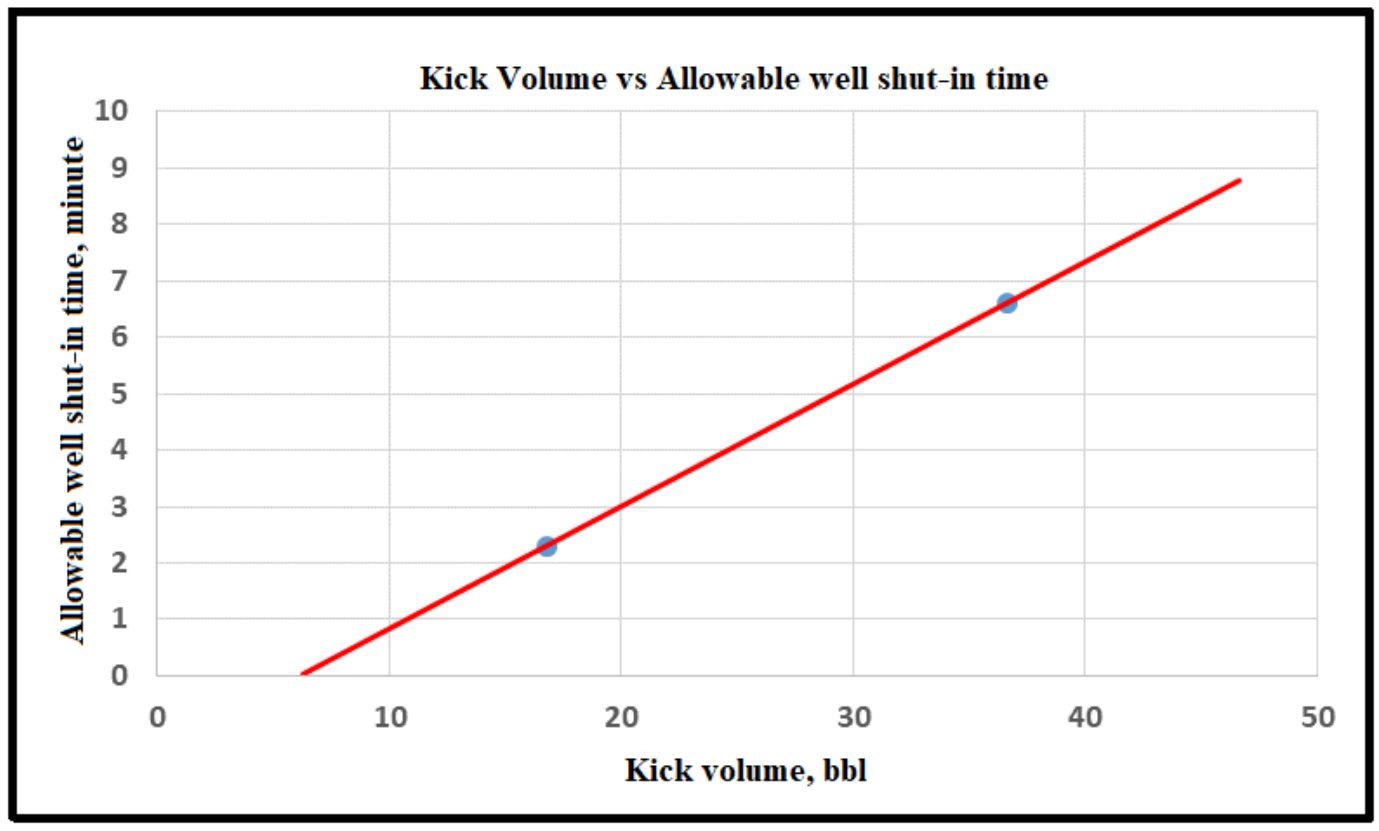

Figure 15: Kick volume vs allowable well shut-in time 


\section{Conclusion and recommendation}

In order to meet the need of the oil and gas industry for innovative drilling technology this research study has been conducted to perform the necessary analysis and develop a methodology for presenting the importance of early kick detection in casing while drilling operations.

- The primary goal of casing while drilling technology is to assist in driving the casing as deep as possible in order to close the troublesome zone. To achieve this goal, numerous operational and engineering tasks were required to assure that this system could be used.

- From the well control side of view, narrow annular clearance and varied pipe geometries that are distinct from drilling with drill pipe would result influx height longer than conventional drilling method creating higher choke and casing shoe pressures as the kick reaches the surface earlier.

- The introduced kick tolerance calculation assumes a volume of gas that has already entered the wellbore has risen to the casing shoe depth, to avoid casing shoe breaking, the volume of the influx should be established (weakest point in wellbore). However, necessitate modifications to earlier well control systems in order to use $\mathrm{CwD}$ technology.

- The study's findings revealed a considerable reduction in kick tolerance and allowable well shut-in time for $\mathrm{CwD}$ technique and according to this analytical study, with more well control considerations related to kick tolerance and choosing appropriate early kick detection instruments, a complete engineering analysis must be performed during the initial start-up and design phase that more performance enhancement and well control optimization can be obtained.

- In order to assess the management of well control events and enhance drilling performance, the well control condition, such as unwanted formation influx events, maximum kick tolerance of the formations and allowable well shut-in time, must be evaluated in any given well. And choosing appropriate early kick detection instruments during the initial start-up and design phase to result more performance enhancement and well control optimization.

- Demonstrate the technology's efficacy in reducing the dangers associated with traditional drilling, which might easily result in the well being lost and further unplanned sidetracks 
- By implication, the kick detection capabilities of rig equipment and employees, as well as the competency of rig operating staff to handle well-control events using best practises, are the main points of considerable attention in this approach.

- The findings of this study imply that there is still a window of opportunity for improving casing while drilling technology by addressing well control throughout the design phase

- It is possible to export the kick tolerance estimations and associated probability derived in this study to another operating business. The outcomes are different from the reservoir engineering and drilling engineering in which the historical records were created, nevertheless, the techniques of this methodology can be used in any established framework on their own. A key assumption in all circumstances is that well control incidents may be successfully managed in a consistent manner using verifiable effectiveness in terms of well control equipment reliability, efficiency, and staff competency. 
Nomenclature

Abbreviations

$\begin{array}{ll}\text { CwD } & \text { Casing while Drilling } \\ \text { EKD } & \text { Early Kick Detection } \\ \text { KT } & \text { Kick Tolerance, bbl } \\ \text { APL } & \text { Annular Pressure Loss, psi } \\ \text { TD } & \text { Total Depth, ft } \\ \text { DLA } & \text { Drill Lock Assembly } \\ \text { BHA } & \text { Bottom Hole Assembly } \\ \text { PDC } & \text { Polycrystalline Diamond Compact } \\ \text { NPT } & \text { Non-Productive Time } \\ \text { KPI } & \text { Key Performance Indicators } \\ \text { KDV } & \text { Kick Detection Volume, bbl } \\ \text { KRT } & \text { Kick Response Time, min } \\ \text { WBM } & \text { Water Based Mud } \\ \text { BOP } & \text { Blowout Preventer }\end{array}$

\section{Symbols}

Z

HP

TVD $_{\text {kick }}$ pmud

AV

$D_{\text {hole }}$

$D_{\text {pipe }}$

$\mathrm{D}_{\text {casing }}$

BHP

FP

FPG

$\mathrm{V}$

$\rho_{\text {overburden }}$

D

TVD $_{\text {shoe }}$

G

$\mathrm{H}_{\text {kick }}$

$\mathrm{Ca}$

$\mathrm{D}_{\mathrm{h}}$

$\mathrm{D}_{\mathrm{p}}$

P1

T1

$\mathrm{P} 2$
Gas Compressibility Factor

Hydrostatic Pressure, psi

kick True Vertical Depth, $\mathrm{ft}$

Mud Weight, ppg

Annular Velocity, ft/min

Hole Diameter, in

Drill Pipe Outside Diameter, in

Casing Outside Diameter, in

Bottomhole Pressure, psi

Formation Pressure, psi

Formation Pressure Gradient, psi/ft

Poisson ratio

Overburden Stress Gradient, psi/ft

True Vertical Depth of Weakest Point in Open Hole Section, $\mathrm{ft}$

True Vertical Depth of Casing Shoe, $\mathrm{ft}$

Gas kick pressure gradient, $\mathrm{psi} / \mathrm{ft}$

Kick Height, $\mathrm{ft}$

Annular Capacity, bbl/ft

Hole Diameter, in

Drillpipe Diameter, in

Fracture pressure at shoe, psi

Temperature at shoe, $\mathrm{F}^{\circ}$

Formation pressure at the kick zone, psi 
T2

MAASP

Qinflux

$\mathrm{K}$

$\Delta \mathrm{P}$

$\mathrm{L}$

$\mu$

$\operatorname{Re}$

$\mathrm{Rw}$
Temperature at kick zone, $\mathrm{F}^{\circ}$

Maximum Allowable Annular Surface Pressure, psi

Influx Flow Rate, bbl/min

Permeability, md

Differential Pressure, psi

length of drilled section in overbalanced formation, $\mathrm{ft}$

Gas viscosity, cp

Radius of drainage, $\mathrm{ft}$

Radius of wellbore, $\mathrm{ft}$ 


\section{References}

1. Gupta, A.K.: "Drilling with Casing: Prospects and Limitations" SPE Western Regional/AAPG Pacific Section/GSA Cordilleran Section Joint Meeting, Anchorage, Alaska, SPE 99536. May 8-10, 2006.

https://doi.org/10.2118/99536-MS

2. M.M. Hossain; M.M. Amro. "Prospects of Casing While Drilling and the Factors to be Considered During Drilling Operations in Arabian Region" IADC/SPE Asia Pacific Drilling Technology Conference and Exhibition, Kuala Lumpur, Malaysia, SPE87987-MS, September 13-15, 2004.

https://doi.org/10.2118/87987-MS

3. Fontenot. Highnote, J., Warren, T., and Houtchens, B., "Casing Drilling Activity Expands in South Texas” SPE/IADC Drilling Conference, Amsterdam, SPE-79862, Feb 19-21, 2003.

https://doi.org/10.2118/79862-MS

4. Tommy M. Warren; Per Angman; Bruce Houtchens.: "Casing Drilling Application Design Considerations". IADC/SPE Drilling Conference, New Orleans, Louisiana, February 2000. SPE-59179-MS.

https://doi.org/10.2118/59179-MS

5. Abubakar, M., Chika, J. O. and Ikebudu, A. O. "Current Trends and Future Development in Casing Drilling" International Journal of Science and Technology, 2(8), pp. 567-582, 2012

\section{https://www.researchgate.net/publication/266885316}

6. B. Marbun, Y. Adinugratama, Bramantyo E. Kurnianto. "Feasibility Study of Casing While Drilling Application on Geothermal Drilling Operation" Thirty-Ninth Workshop on Geothermal Reservoir Engineering Stanford University, Stanford, California, February 24-26, 2014.

https://pangea.stanford.edu/ERE/pdf/IGAstandard/SGW/2014/Marbun2.pdf

7. Pavković Bojan1, Bizjak Renato1, Petrović Bojan. "Review of Casing while Drilling Technology". Underground Mining Engineering 29, University of Belgrade - Faculty of Mining and Geology, December 10, 2016 
8. O. Grijalva; J.. Holzmann; J. Oppelt; N. Perozo; C. Paz; A. Asgharzadeh. "OCTG Advancements in Casing Drilling: Where We Have Been and Where Are We Going?" SPE Oklahoma City Oil and Gas Symposium, SPE-185102-MS. March 27-31, 2017. https://doi.org/10.2118/185102-MS.

9. Yash Gupta; Sudeepto Nilmani Banerjee. "The application of expandable tubulars in casing while Drilling". SPE Production and Operations Symposium, Richardson, Texas, March-31 April-3, 2007.

https://doi.org/10.2118/105517-MS

10. Brian Tost, Kelly Rose, Fred Aminzadeh, Magdalene A. Ante, Nicolas Huerta. "Kick Detection at the Bit: Early Detection via Low Cost Monitoring". National Energy Technology Laboratory, 1450 Queen Avenue SW, Albany, OR 97321. 7 June 2016. https://www.osti.gov/servlets/purl/1327810/

11. Bonar Noviasta; Hanafi Muhamad Falhum; Budi Setiawan. "Innovative Casing Drilling Technology Improved the Ability to Set the Casing Deeper Through the Problematic Zone in Indonesia Geothermal Operation". Abu Dhabi International Petroleum Exhibition \& Conference. SPE-188960-MS. November 13-16, 2017. https://doi.org/10.2118/188960-MS

12. Dipal Patel, Manan Shah, Vivek Thakar, Anirbid Sircar. "Identifying Casing While Drilling (CwD) Potential in Geothermal Scenario Along with Economics". 44th Workshop on Geothermal Reservoir Engineering Stanford University, Stanford, California, February $11-13,2019$.

https://pangea.stanford.edu/ERE/pdf/IGAstandard/SGW/2019/Patel.pdf

13. Ossama Sehsah; Amir El Kawass; Syed Muhamad Siddik; Ahmed Refai; Syed Zahoor Ullah; Abdulqawi Al Fakih; Jeremy Halma; Ahmed Aboul Enein; Mohammed Sami Almomen; Ahmed Subhi Alatiyyah. "Casing While Drilling Transformation into Standard Operation in Middle East". International Petroleum Technology Conference. Dhahran, Kingdom of Saudi Arabia. January 13-15, 2020. IPTC-19730-MS. https://doi.org/10.2523/IPTC-19730-MS

14. A. Kerunwa1, C. I. C. Anyadiegwu. "Overview of the advances in casing drilling technology". Petroleum \& Coal 57(6) 661-675, 2015

15. Moji Karimi; Scott Petrie; Eric Moellendick; Calvin Holt. "A Review of Casing Drilling Advantages to Reduce Lost Circulation, Improve Wellbore Stability, Augment Wellbore Strengthening, and Mitigate Drilling-Induced Formation Damage" 
SPE/IADC Middle East Drilling Technology Conference and Exhibition.. Muscat, Oman. SPE-148564-MS, October 24-26, 2011.

https://doi.org/10.2118/148564-MS

16. Bonar T. H. Marbun, Widiyanto, Yudhistira Adinugratama, and Bramantyo E. Kurnianto.

"Feasibility Study of Casing While Drilling Application on Geothermal Drilling Operation". Thirty-Ninth Workshop on Geothermal Reservoir Engineering Stanford University, Stanford, California, February 24-26, 2014.

https://www.semanticscholar.org/paper/Feasibility-Study-of-Casing-While-Drillingon-Marbun-Adinugratama/b2a8c8cc5d812a3c79c02b88453dc19417aa2498

17. E.. Beaumont; L.. de Crevoisier; F.. Baquero; J.. Sanguino; D.. Herrera; E.. Cordero. "First Retrievable Directional Casing While Drilling (DCwD) Application in Peruvian Fields Generates Time Reduction and Improves Drilling Performance Preventing Potential Non-Planned Downtime" SPE Latin American and Caribbean Petroleum Engineering Conference, Lima, Peru, SPE-139339-MS. December 1-3, 2010.

https://doi.org/10.2118/139339-MS

18. O. Grijalva Meza, K.. Kamp, A.. Asgharzadeh, O.. Bello, R.. Freifer, J.. Oppelt. "Well Control for Drilling with Casing: Theoretical and Experimental Insights into Hydraulic Behavior in Small Annular Clearances". SPE/IADC Middle East Drilling Technology Conference and Exhibition, SPE-189366-MS. January 29-31, 2018.

https://doi.org/10.2118/189366-MS

19. Dipal Patel, Vivek R Thakar, Sivakumar Pandian, Manan Shah, Anirbid Sircar. "A review on casing while drilling technology for oil and gas production with well control model and economical analysis". Petroleum. December 2018. Volume 5, Issue 1, March 2019, Pages 1-12.

https://www.researchgate.net/publication/329598671

20. Carolina Silva Avelar, Paulo Roberto Ribeiro. "The study of well planning using the kick tolerance concept" 18th International Congress of Mechanical Engineering. November 6-11, 2005.

https://www.abcm.org.br/anais/cobem/2005/PDF/COBEM2005-2487.pdf

21. Adetola D. Dedenuola; Isaac E. Iyamu; Olayinka A. Adeleye. "Stochastic Approach to Kick Tolerance Determination in Risk Based Designs" SPE Annual Technical Conference and Exhibition, Denver, Colorado, SPE-84174-MS. October 5-8, 2003, https://doi.org/10.2118/84174-MS 
22. Nagham Jasim Al-Ameri. "Kick tolerance control during well drilling in southern Iraqi deep wells", Iraqi Journal of Chemical and Petroleum Engineering, Vol.16 No.3, September 2015

https://www.researchgate.net/publication/343080303

23. D. Fraser; R. Lindley; D. Moore; M. Vander Staak. "Early Kick Detection Methods and Technologies". SPE Annual Technical Conference and Exhibition. Amsterdam, the Netherlands. SPE-170756-MS. October 27-29, 2014.

https://doi.org/10.2118/170756-MS

24. S.H.L. Parfitt; J.L. Thorogood. "Application of QRA Methods to Casing Seat Selection" European Petroleum Conference, London, United Kingdom, SPE-28909-MS. October 25-27, 1994.

https://doi.org/10.2118/28909-MS 


\section{APPENDIX}

\section{A. Kick tolerance \& Allowable well shut-in time calculations based on conventional drilling technique.}

1. Hydrostatic pressure $(H P)$ at kick depth, psi

$$
\begin{gathered}
H P=0.052 * \rho \text { mud } * \text { TVDkick } \\
H P=0.052 * 9.1 * 2145=1015 p s i
\end{gathered}
$$

2. Annular pressure loss (APL) at kick depth, psi

$$
\begin{gathered}
A P L=\frac{\left(1.4327 * 10^{-7}\right) * \text { pmud } * \text { TVD kick } * A V^{2}}{\text { Dhole }- \text { Dpipe }} \\
A P L=\frac{\left(1.4327 * 10^{-7}\right) * 9.1 * 2145 * 175^{2}}{12 \frac{1}{4}-5}=11.4 p s i
\end{gathered}
$$

3. Bottom hole pressure (BHP) at kick depth, psi

$$
\begin{gathered}
B H P=H P+A P L \\
B H P=1015+11.4=1026.4 p s i
\end{gathered}
$$

4. Formation pressure $(P f)$ at kick depth, psi

$$
\begin{gathered}
P f=F P G * \text { TVDkick } \\
P f=0.433 * 2145=928.8 \text { psi }
\end{gathered}
$$

5. Formation fracture gradient (FG) at previous casing shoe, ppg By using Hubbert and Willis method as follows: -

$$
\begin{gathered}
F G=\left(\frac{\mathrm{V}}{1-\mathrm{V}}\right) *\left(\frac{\text { poverburden }-P f}{D}\right)+\frac{P f}{D} \\
F G=\left(\frac{0.4}{1-0.4}\right) *\left(\frac{1 * 484-0.433 * 484}{484}\right)+\frac{0.433 * 484}{484}=0.811 \frac{\mathrm{psi}}{\mathrm{ft}}=15.6 \mathrm{ppg}
\end{gathered}
$$

6. Maximum allowable gas kick height at casing shoe $\left(H_{\text {kick }}\right)$, ft

$$
\begin{aligned}
& \text { Hkick }=\frac{0.052 * \rho m u d *(\text { TVDkick }- \text { TVDshoe })+F G * \text { TVDshoe } * 0.052-P f}{0.052 * \text { pmud }-G} \\
& H k i c k=\frac{0.052 * 9.1 *(2145-484)+15.6 * 484 * 0.052-0.433 * 2145}{0.052 * 9.1-0.102}=673 \mathrm{ft}
\end{aligned}
$$

7. Maximum kick volume at casing shoe (V1), bbl

$$
\begin{gathered}
V 1=C a * \text { Hkick } \\
C a=\frac{D h^{2}-D p^{2}}{1029.4} \\
C a=\frac{\left(12 \frac{1}{4}\right)^{2}-(5)^{2}}{1029.4}=0.1214 \mathrm{bbl} / \mathrm{ft} \\
V 1=0.1214 * 673=81.7 \mathrm{bbl}
\end{gathered}
$$


8. Maximum kick volume (V2) at the bottom, bbl

By using Boyle's Law: -

$$
\frac{P 1 * V 1}{T 1}=\frac{P 2 * V 2}{T 2}
$$

Where: -

Condition\#1 at the last casing shoe

Condition\#2 at the bottom

$$
\begin{gathered}
T 1=60+0.02 * 484+460=529 R^{\circ} \\
T 2=60+0.02 * 2145+460=562 R^{\circ} \\
\frac{15.6 * 0.052 * 484 * 81.7}{529}=\frac{0.433 * 2145 * V 2}{562}
\end{gathered}
$$

$$
\mathrm{V} 2=36.6 \mathrm{bbl}
$$

$1^{\text {st }}$ case: $\mathrm{V} 1=81.7 \mathrm{bbl}$

$2^{\text {nd }}$ case: $\mathrm{V} 2=36.6 \mathrm{bbl}$

Therefore, the maximum allowable influx volumes (kick tolerance) is $36.6 \mathrm{bbl}$.

9. Maximum allowable annular surface pressure (MAASP), psi with zero kick volume

$$
\begin{gathered}
\text { MAASP }=0.052 *(F G-\rho m u d) * \text { TVDshoe } \\
M A A S P=0.052 *(15.6-9.1) * 484=163.6 p s i
\end{gathered}
$$

10. According to formation properties, estimate influx flow rate (Qinflux) after drill $20 \mathrm{ft}$ into kick zone using Equation.11

$$
\begin{gathered}
\text { Qinflux }=\frac{0.007 * \mathrm{~K} * \Delta \mathrm{p} * L}{\mu * \ln \frac{R e}{R w} * 1440} \quad E q .11 \\
\text { Qinflux }=\frac{0.007 * 500 * 200 * 20}{0.3 * \ln \frac{400}{0.354} * 1440}=4.6 \mathrm{bbl} / \mathrm{min}
\end{gathered}
$$

11. Based on influx flow rate (Qinflux) and After kick tolerance is determined, 5 bbl. because of pit gain alarm setting and $1 \mathrm{bbl}$. because of safety reasons have to be subtracted from it. the estimated shut-in time limit can be calculated using Equation.12

Maximum Allowable Well Shut in Time $=\frac{\text { Maximum Allowable Kick Tolerance }}{\text { Qinflux }}$ Eq.12

$$
\text { Maximum Allowable Well Shut in Time }=\frac{30.6}{4.6}=6.6 \mathrm{~min}
$$


B. Kick tolerance \& Allowable well shut-in time calculations based on casing while drilling technique

1. Hydrostatic pressure $(H P)$ at kick depth, psi

$$
\begin{gathered}
H P=0.052 * \rho \text { mud } * \text { TVDkick } \\
H P=0.052 * 9.1 * 2145=1015 \text { psi }
\end{gathered}
$$

2. Annular pressure loss $(A P L)$ at kick depth, psi

$$
\begin{gathered}
A P L=\frac{\left(1.4327 * 10^{-7}\right) * \text { omud } * \text { TVDkick } * A V^{2}}{\text { Dhole }- \text { Dcasing }} \\
A P L=\frac{\left(1.4327 * 10^{-7}\right) * 9.1 * 2145 * 175^{2}}{12 \frac{1}{4}-9 \frac{5}{8}}=32.6 p s i
\end{gathered}
$$

3. Bottom hole pressure (BHP) at kick depth, psi

$$
\begin{gathered}
B H P=H P+A P L \\
B H P=1015+32.6=1047.6 p s i
\end{gathered}
$$

4. Formation pressure $(P f)$ at kick depth, psi

$$
\begin{gathered}
P f=F P G * T V D \text { kick } \\
P f=0.433 * 2145=928.8 \text { psi }
\end{gathered}
$$

5. Formation fracture gradient $(F G)$ at previous casing shoe, ppg By using Hubbert and Willis method as follows: -

$$
\begin{gathered}
F G=\left(\frac{\mathrm{V}}{1-\mathrm{V}}\right) *\left(\frac{\text { poverburden }-P f}{D}\right)+\frac{P f}{D} \\
F G=\left(\frac{0.4}{1-0.4}\right) *\left(\frac{1 * 484-0.433 * 484}{484}\right)+\frac{0.433 * 484}{484}=0.811 \frac{\mathrm{psi}}{\mathrm{ft}}=15.6 \mathrm{ppg}
\end{gathered}
$$

6. Maximum allowable gas kick height at casing shoe $\left(H_{\text {kick }}\right), \mathrm{ft}$

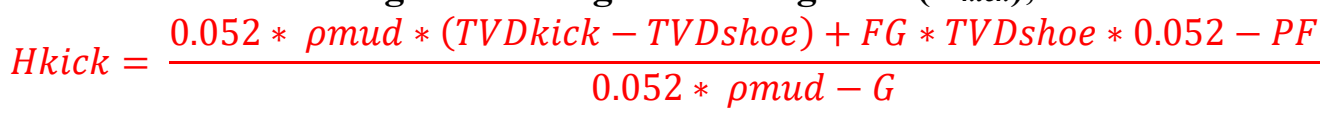

$$
H k i c k=\frac{0.052 * 9.1 *(2145-484)+15.6 * 484 * 0.052-0.433 * 2145}{0.052 * 9.1-0.102}=673 \mathrm{ft}
$$

7. Maximum gas kick volume at casing shoe (V1), bbl

$$
\begin{gathered}
V 1=C a * \text { HKick } \\
C a=\frac{D h^{2}-D p^{2}}{1029.4} \\
C a=\frac{\left(12 \frac{1}{4}\right)^{2}-\left(9 \frac{5}{8}\right)^{2}}{1029.4}=0.0558 \mathrm{bbl} / \mathrm{ft} \\
V 1=0.0558 * 673=37.5 \mathrm{bbl}
\end{gathered}
$$


8. Maximum gas kick volume (V2) at bottom, bbl

By using Boyle's Law: -

Where: -

$$
\frac{P 1 * V 1}{T 1}=\frac{P 2 * V 2}{T 2}
$$

Condition\#1 at the last casing shoe

Condition\#2 at the bottom

$$
\begin{gathered}
T 1=60+0.02 * 484+460=529 R^{\circ} \\
T 2=60+0.02 * 2145+460=562 R^{\circ} \\
\frac{15.6 * 0.052 * 484 * 37.5}{529}=\frac{0.433 * 2145 * V 2}{562} \\
\mathrm{~V} 2=16.8 \mathrm{bbl}
\end{gathered}
$$

$1^{\text {st }}$ case: $\mathrm{V} 1=37.5 \mathrm{bbl}$

$2^{\text {nd }}$ case: $\mathrm{V} 2=16.8 \mathrm{bbl}$

Therefore, the maximum allowable influx volumes (kick tolerance) is $16.8 \mathrm{bbl}$.

9. Maximum allowable annular surface pressure (MAASP), psi with zero kick volume

$$
\begin{gathered}
\text { MAASP }=0.052 *(F G-\rho \text { mud }) * \text { TVDshoe } \\
M A A S P=0.052 *(15.6-9.1) * 484=163.6 p s i
\end{gathered}
$$

10. According to formation properties, estimate influx flow rate (Qinflux) after drill $20 \mathrm{ft}$ into kick zone using Equation.11

$$
\begin{gathered}
\text { Qinflux }=\frac{0.007 * \mathrm{~K} * \Delta \mathrm{p} * L}{\mu * \ln \frac{R e}{R w} * 1440} \quad E q .11 \\
\text { Qinflux }=\frac{0.007 * 500 * 200 * 20}{0.3 * \ln \frac{400}{0.354} * 1440}=4.6 \mathrm{bbl} / \mathrm{min}
\end{gathered}
$$

11. Based on influx flow rate (Qinflux) and After kick tolerance is determined, 5 bbl. because of pit gain alarm setting and $1 \mathrm{bbl}$. because of safety reasons have to be subtracted from it. the estimated shut-in time limit can be calculated using Equation.12

Maximum Allowable Well Shut in Time $=\frac{\text { Maximum Allowable Kick Tolerance }}{\text { Qinflux }}$ Eq.12

$$
\text { Maximum Allowable Well Shut in Time }=\frac{10.8}{4.6}=2.3 \mathrm{~min}
$$




\section{Supplementary Files}

This is a list of supplementary files associated with this preprint. Click to download.

- Figure.rar 